\title{
Hypocrisy and Moral Justification: Do Consequences and Reasons Make a Difference?
}

\section{VINOJA VIJAYASINGAM, ZAKIA HUSSAIN, AND KOSHA BRAMESFELD}

Department of Psychology, University of Toronto Scarborough, Canada

\section{Abstract}

Hypocrites are negatively judged for creating false perceptions of their own morality while condemning the morality of others. In this experiment, we examined whether an act of hypocrisy would be judged as more morally justified if it led to a lenient consequence versus a harsh consequence for another person and was explained with an other-focused versus self-focused reason. The experiment was implemented via an online study using a $3 \times 3$ between-groups factorial design that manipulated the consequences of, and reasons for, an act of hypocrisy. We found that hypocrisy that led to a harsh consequence for another person was viewed as less morally justified than the same harsh act that occurred in the absence of hypocrisy or when hypocrisy led to a lenient consequence for another person. The reason given for the hypocritical act did not impact perceptions of moral justification, nor was there an interaction between consequences and reasons. These results support the hypothesis that hypocrisy was judged negatively because it led to harsh consequences for others. However, our research leaves open the question of whether hypocrisy can be morally justified with a compelling reason.

Keywords: hypocrisy, consequence, reason

\section{Introduction}

Hypocrisy can be defined as a "behaviour that contradicts what one claims to believe or feel" (Merriam-Webster Online Dictionary, n.d.). However, contradiction alone fails to capture the extent to which hypocrisy generates strong feelings of loathing in people (Jordan et al., 2017). Jordan et al. (2017) found that the dislike of hypocrites was so strong that hypocrisy was seen as evidence of a person's core moral character, even when the act of hypocrisy occurred within the context of morally ambiguous acts, such as illegally downloading music (Jordan et al., 2017), and when the hypocrite tried to repent (Kreps et al., 2017). The hypocrisy that creates the perception of one's own moral superiority while contrarily acting against one's moral beliefs is known as moral hypocrisy (Batson \& Thompson, 2001; Jordan et al., 2017). Given the intensity of the negative judgements on moral hypocrisy, it is important to examine the factors that drive perceptions of hypocrisy. 
Moral character seems to matter most in informing judgements of a person (Goodwin et al., 2014). Moral hypocrisy allows a person to appear moral, without actually having to do the work of being moral (Batson \& Thompson, 2001). Jordan et al. (2017) suggested that hypocrites were perceived as morally repugnant, not only because they gave false signals of their own goodness, but because they condemned the morality of others in the process. In their discussion of hypocrisy, Jordan et al. posited that harm (i.e. negative consequences) to others was a key reason why hypocrisy was morally condemned. We will explore literature examining how the consequences of a hypocritical act influence perceptions of hypocrisy and if the reasons for hypocrisy can morally justify the action.

\section{Consequences of Hypocrisy}

The notion that the consequences of an action will be taken into consideration when making a judgment of behaviour is referred to as outcome bias (Baron \& Hershey, 1988). Baron and Hershey (1988) found that when a decision was framed as having a positive outcome, it was rated more positively than when the same decision was framed as having a negative and unfavourable outcome. As such, outcome bias may moderate judgements of hypocrisy. Alicke et al.'s (2013) research provided initial support for the idea that manipulating the consequences of a hypocritical act can moderate judgements of hypocrisy. Participants evaluated three scenarios with the manipulated consequences as either positive or negative. Alicke et al. found that consequences moderated perceptions of hypocrisy only in one scenario. The scenario was perceived as less hypocritical when the consequence was positive rather than negative. In the other two scenarios, judgements of hypocrisy were low regardless of whether the consequence was positive or negative. No moderating effects of positive or negative consequences were found because the two scenarios were perceived as being low in hypocrisy. In addition, Alicke et al. did not manipulate the presence or absence of hypocrisy, so it was difficult to know if judgements of hypocrisy were tied to the hypocritical act, the consequence, or a combination of both.

\section{Reasons for Hypocrisy}

Hypocrites are judged harshly because their act of hypocrisy is seen as advancing their own moral position at the expense of others (Jordan et al., 2017). However, if a person had a good reason for engaging in a hypocritical act, would they still be judged harshly for their hypocrisy?

Effron and Monin (2010) found that strong history of prosocial behaviour could serve as a protective factor against negative judgements after a transgression. Still, the authors focused on good deeds that occurred prior to a transgression. 
Research by Barden et al. (2005) established that the temporal order of reasoning influenced judgements of hypocrisy. Barden et al. found that targets who provided a contradictory values statement after a transgressing act were perceived more positively than targets who first made a statement that established a values standard and then acted in a way that was contradictory to that standard. Nonetheless, Barden et al.'s research did not examine if a change of opinion after a contradiction would be perceived favourably. The question remains: What would happen if a person were to (a) signal moral goodness at one point in time, (b) transgress that moral signalling at another point in time, and then (c) tried to provide an explanation for their transgression after the fact?

Kreps et al. (2017) provided one potential answer by examining what happened when public figures took a public stand on a position for moral versus practical reasons and then later changed their mind. Kreps et al. found that even when people provided reasons for their change in mind they were still perceived as hypocrites if they had taken an initial moral versus pragmatic stance on an issue. The initial moral statement was perceived as the "true" opinion, with later statements being seen as a contradiction of that initial stance, rather than a genuine change in mind.

Yet, what if the explanation provided was not intended to explain a change in mind, but to justify the hypocritical act as "morally good" instead? Alicke et al. (2013) predicted that behaving hypocritically for prosocial reasons would reduce perceptions of hypocrisy. They studied this issue across two scenarios. One scenario was perceived as less hypocritical when a prosocial reason for acting hypocritically was given, compared to a selfish reason. The second scenario was judged as being low in hypocrisy regardless of whether it was for a prosocial or selfish reason. Given these mixed findings, more research is needed to examine if giving a prosocial reason for hypocrisy can mitigate negative judgements.

\section{The Current Study}

Harm to others has often been a defining feature of hypocrisy (Baron \& Hershey, 1988; Jordan et al., 2017). Yet, very little research has directly manipulated harm to others to examine its moderating influence. The research that has directly examined this topic remains exploratory and mixed (e.g., Alicke et al., 2013). Likewise, it is unclear to what extent outrage about hypocrisy occurs specifically because it signals moral goodness in a self-serving manner. If someone were to engage in a contradictory act to help others, would this be enough to mitigate negative judgements? More research is needed to directly examine the extent to which consequences for others, and 
reasons for action, moderate judgements of hypocrisy.

In our research, we asked the following questions: If hypocrisy is judged negatively because it is viewed as advancing one's own moral position at the expense of others, would a hypocritical act be perceived as more morally justified if it led to a lenient consequence, rather than a harsh consequence for another person? Would it matter if the hypocritical act occurred for an other-focused reason (i.e., an altruistic act done for the benefit of others), rather than a self-focused reason (i.e., to advance one's own standing or benefit oneself)?

In the current study, we used a mock news article to manipulate the extent to which a public official (a police officer) made a public stand for or against a jaywalking law before being caught in the act of giving (or not giving) a citation to a jaywalker. Jaywalking is a traffic violation defined as illegally crossing a street at a location other than a designated crosswalk. According to the Centers for Disease Control (CDC, 2017), pedestrians are 1.5 times more likely to be killed in a traffic accident than are passengers in a vehicle. Pedestrians under the age of 15 and over the age of 65 are at the highest risk for pedestrian death and injury (CDC, 2017). Despite these statistics, jaywalking is perceived mostly as a morally ambiguous action (Moon et al., 2017). Jordan et al. (2017) noted that morally ambiguous tasks may provide an ideal context for studying hypocrisy as these tasks give room for subjects to assess the scenarios without heavy biases. Jaywalking was ideal for our purposes, as it provided us with a context to manipulate whether an act of hypocrisy resulted in a harsh versus lenient consequence for another person (i.e., being issued a citation vs. not). It also allowed us to manipulate an other-focused versus self-focused reason for the hypocrisy (i.e. to advance public safety or the officer's own career).

To increase the external validity of the jaywalking scenario, we used the pedestrian risk of death and injury statistics identified by the CDC to write a "high risk" jaywalking scenario in which a police officer witnesses a woman in her 70 s cross a busy urban street mid-block after exiting a city bus. Although pedestrian fatalities are higher at night (CDC, 2017), we situated the scenario in the daytime to increase believability that the police officer correctly witnessed the event. We also focused on an older adult pedestrian, rather than a child, as an adult pedestrian would be more likely to receive a citation for jaywalking. Experimental outcomes were assessed using a series of self-report questions measured on a 7point Likert-type scale, with 1 corresponding to "strongly disagree".

We hypothesized that hypocritical actions would be judged as less morally justified when they resulted in a harsh consequence 
versus a lenient consequence affecting another. We also hypothesized that a hypocritical act would be judged as more morally justified when the actions were explained with an other-focused reason versus a self-focused reason.

\section{Methods}

The procedures and methods of this experimental study were developed by undergraduate students enrolled in an undergraduate laboratory course focused on social psychological research methods. The survey materials, along with the data and SPSS syntax files used for the analyses have been archived (see Supplementary Materials).

\section{Participants}

Recruitment. We sought to recruit 158 participants to achieve $80 \%$ power with a significance level of $a=.05$ and an anticipated medium effect size of $f=0.25$ (equivalent to $\eta 2>0.06$ ). After acquiring Research Ethics Board approval (REB: PSYSC-CB-2019-001KD), we used a convenience sampling method to recruit participants via social media, email, course announcements, and research recruitment websites.

Sample. A total of 156 respondents consented to participate in the study and submitted a survey. Prior to the analysis, 12 of the respondents were excluded from the study because they (a) spent less than 2 minutes on the survey and/or completed fewer than half of the items presented to them $(N=6)$, or (b) failed the survey attention check $(N=6)$. The final sample included 144 participants. Because we did not achieve our targeted sample size, we conducted a sensitivity analysis $(80 \%$ power and $a=.05$ ) to determine the size of the effects we could detect given our actual sample size (Faul et al., 2007). Our analyses indicated that we could detect effects equal to or greater than $f=0.33$ (equal to $\eta 2=0.10$ ). Given this, we determined an effect statistically significant only if $p<.05$ and $\eta 2>0.10$.

Participant Demographics. The participants lived in Canada (68.8\%), the United States (21.5\%), or outside of Canada and the United States (9.7\%), and identified as female $(71.5 \%)$, male $(27.1 \%)$, or nonbinary (1.4\%). We found no significant differences in perceptions of moral hypocrisy by gender, $p=.23$, with a small effect size, $d$ $=0.20$. The participants were all 18 or older, with $75.2 \%$ of participants indicating an age range of $18-25$ years old and $95 \%$ of participants reporting an age of 60 years of age or younger. The association between age and moral hypocrisy was not statistically significant and the effect size was small, $r s$ (142) = -.15 and $p=.07$.

\section{Experimental Manipulation and Procedures}

After reading a consent statement, participants were presented with a demographic survey asking about their 
geographic location, gender, and age (three items). Participants were then presented with one of nine variants of an online news article created by the researchers. The news article was used to manipulate the consequences and reasons for hypocrisy in a $3 \times 3$ between-groups design, as described below.

The news article reported on a scenario in which an officer holds a press conference to take a moral stand in support of or in opposition to a jaywalking law. The news article also explains that later that month the same officer was caught on video giving (or not giving) a citation to a woman in her 70s who crossed a busy urban street mid-block after exiting a city bus.

In the harsh hypocrisy condition, the officer takes a stand against a jaywalking law but issues a citation anyway. In the lenient hypocrisy condition, the officer takes a stand in favour of a jaywalking law but does not issue a citation. Finally, in the no hypocrisy control condition, the officer takes a stand in favour of a jaywalking law and, consistent with that position, issues a citation. When asked about the reasons for these actions, the officer gave an other-focused reason, a self-focused reason, or no reason. All other aspects of the article were identical and held constant across conditions.

After reading the news article, participants responded to two sets of questions. Set $A$ included four items assessing participants' interest in the article and five items that served as a check of the participant's attention to the article. Set B included 41 items that assessed the participants' perceptions of the officer's motives, behaviour, reactions to the situation, moral character, and similarity to the participant's own likely reactions within the same context. The presentation of question sets $A$ and $B$ were randomized to control for potential order effects. All rating items were measured on a 7 -point Likert-type scale, with 1 corresponding to "strongly disagree".

\section{Measured Variables}

Attention checks. To identify potentially unmotivated responders, we included five items in the survey that served as an attention check. Six participants failed this attention check and were excluded from the analysis.

Manipulation and Control Checks. To test the effectiveness of the manipulation, we assessed the degree to which the scenario was perceived as contradictory (five items, $a=.84$ ), harsh (two items, $a=.77$ ), otherfocused (six items, $a=.62$ ), typical behaviour for the officer (four items, $a=$ .70 ), and interesting (four items, $a=.72$ ). These measures confirmed that the manipulations were successful in creating the desired conditions and that the conditions did not differ in their perceived interest. 
Moral Justification. A total of 23 items were created to measure three aspects of our dependent variable, moral justification. First, we created eight items to measure perceptions of whether the officer's actions were generally justified. Second, inspired by Jordan et al. (2017), we created 10 items that measured perceptions of the officer's moral character. Third, we created five items to measure perceptions of how the participant thought they would respond in the same situation.

A principal component analysis of the 23 items revealed three components with eigenvalues greater than 1.0. These components explained $50 \%, 11 \%$, and $7 \%$ of the total variance. However, an examination of the scree plot, factor loadings, and correlations between the subscales strongly supported a one-factor solution. The scree plot revealed all 23 items had a factor loading greater than 0.40 on the first component, and when the three subscales were considered as separate components, they were all highly correlated, $r>.70$. Given this, all 23 items were averaged together into a single composite variable that represented overall perceptions of moral justification (Cronbach's alpha, $a=.95$, with seven reverse coded items).

\section{Statistical Analysis}

Preliminary analyses were conducted on the manipulation and control checks. A $3 x$
3 analysis of variance (ANOVA) was conducted for each of the three manipulation checks (contradiction, harshness of consequence, reasons with prosocial motive) and revealed expected significant main effects of framing. A $3 \times 3$ ANOVA revealed a small main effect of hypocrisy framing on the typicality of the officer's behaviour. A $3 \times 3$ ANOVA revealed no main effects or interactions related to participant's perceived interest in the media article.

The SPSS Statistics Data Editor program was used to analyze the data for this study. A $3 \times 3$ ANOVA was conducted to examine the between-subjects effects of consequence framing (harsh, lenient, and no hypocrisy) and reasons (other-focused, self-focused, and no reason) on moral justification. Prior to analyzing the data, we checked for the presence of major outliers and for the assumption of normality and homogeneity of variance. The examination of the histograms, Q- $Q$ plots, box plots, and Levine's test of equality of error variances revealed no major violations of these assumptions.

\section{Results}

The hypotheses were assessed with a 3 (harsh vs. lenient vs. no hypocrisy) $\times 3$ (other-focused vs. self-focused vs. no reason) ANOVA to examine ratings of moral justification. Only a significant main effect of consequence framing emerged, $F_{(2,135)}=9.34, p<.001, \eta 2=.12$. The main effect of reasons was not statistically 
Table 1. Mean Ratings of Moral Justification for Framing and Reasoning Conditions

Values presented as means and standard deviations are given in parentheses. Asterisks $\left({ }^{*}\right)$ denote significance between groups. Harsh Hypocrisy: $N=53$. Lenient Hypocrisy: $N=44$. No Hypocrisy Control: $N=47$. OtherFocused Reason: $N=54$. Self-Focused Reason: $N=48$. No Reason: $N=44$.

\begin{tabular}{|l|c|c|c|c|}
\hline & \multicolumn{3}{|c|}{ Hypocrisy Framing } & \\
\hline Reasoning & Harsh & Lenient & No Hypocrisy & Marginal mean \\
\hline Other-focused & $3.83(0.83)$ & $4.90(1.04)$ & $4.62(1.23)$ & $4.45(1.13)$ \\
\hline Self-focused & $4.07(1.02)$ & $4.45(1.10)$ & $4.29(1.08)$ & $4.24(1.05)$ \\
\hline No reason & $3.66(1.23)$ & $4.88(0.41)$ & $4.41(0.92)$ & $4.30(1.03)$ \\
\hline Marginal mean & $3.89 *(1.02)_{\mathrm{a}}$ & $4.74(0.93)_{\mathrm{b}}$ & $4.48(1.09)_{\mathrm{b}}$ & $4.34(1.07)$ \\
\hline
\end{tabular}

significant, $F_{(2,135)}=0.40, p=.67, \eta 2<$ .01 , nor was the interaction between consequence framing and reasons, $F_{(2,135)}$ $=0.86, p=.49, \eta 2=.03$.

Participants viewed the harsh hypocrisy condition as less morally justified ( $M=$ 3.89, SD = 1.02) than either the lenient hypocrisy condition $(M=4.74, S D=0.93)$, $p<.001,95 \% \mathrm{Cl}[-1.31,-0.47], d=-0.87$, or the no hypocrisy condition ( $M=4.48$, SD $=1.09), p=.006,95 \% \mathrm{Cl}[-1.00,-0.17], d$ $=0.56$ (see Table 1 \& Figure 1). Differences between the lenient hypocrisy condition and the no hypocrisy condition were small and not statistically significant, $p=.17,95 \% \mathrm{Cl}[-0.74,0.13], d$ $=0.26$.

\section{Discussion}

If inconsistency alone were enough to determine perceptions of moral justification, we would expect the no hypocrisy condition to be rated as more morally justified than either of the hypocrisy conditions, regardless of the reason for the action or its consequences. However, this was not observed. The no hypocrisy condition was perceived as more morally justified than the harsh hypocrisy condition, but it was not perceived as more morally justified than the lenient hypocrisy condition. This suggests that contradiction alone cannot explain people's harsh reactions to hypocrisy.

We also hypothesized that a hypocritical action would be judged as less morally justified when it resulted in a harsh consequence versus a lenient consequence for another. Participants viewed the harsh hypocrisy condition as less morally justified than either the lenient hypocrisy condition or the no hypocrisy condition, lending support to our hypothesis.

Lastly, we hypothesized that a hypocritical act would be judged as more morally 
Moral Justification for Consequence and Reasoning Hypocrisy Conditions

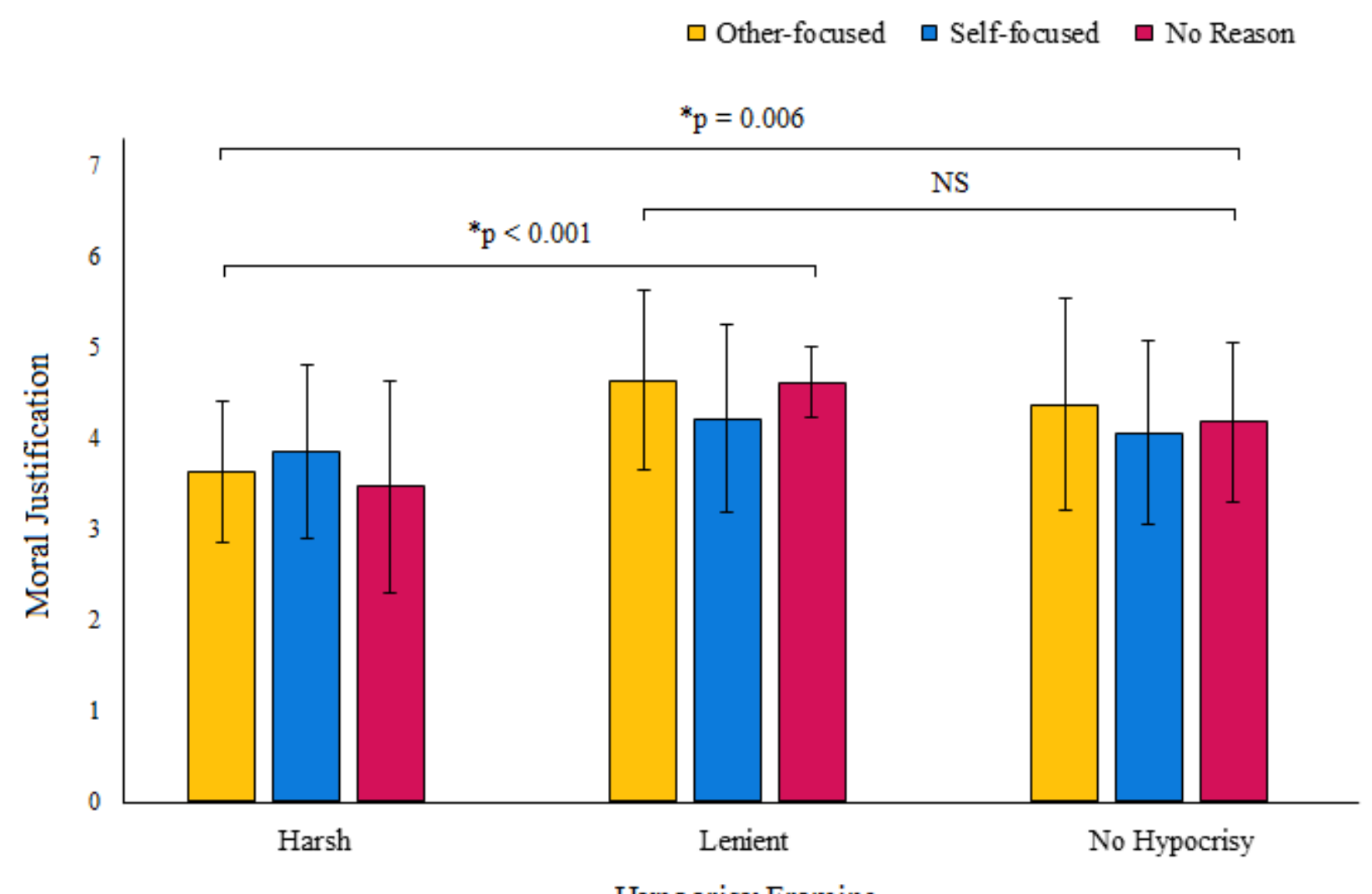

Hypocrisy Framing

Figure 1. The mean participant ratings of moral justification (on a scale from 1, strongly disagree, to 7 , strongly agree) for consequence and reasoning hypocrisy conditions.

Error bars represent the standard deviation of the sample. Brackets show significant differences between consequence framings (asterisks * indicate significant $p$-values and 'NS' indicates the $p$-value is not significant).

justified when the actions were explained with an other-focused reason versus a selffocused reason. Our hypothesis was not supported. We could not detect statistically significant differences for judgements of morality between the otherfocused and self-focused reasons, nor did the reasons interact with the consequences to impact perceptions of hypocrisy.

It is possible that we failed to detect effects with our reason manipulation due to low statistical power. Although our sample size was sufficient for detecting large effect sizes, our power analysis indicated that a sample size of 158 participants or greater would be needed to detect the medium effect sizes typically found within the psychology literature. Until a consistent pattern of null effects can be established across several highpowered studies, it is premature to conclude that reasons do not impact 
perceptions of hypocrisy.

A potential reason why we did not detect differences may be due to a conceptual conflation between the two independent variables. Our manipulation checks suggested that our consequence manipulation altered perceptions of harshness and prosocial motivation. This conflation could have introduced a confound that attenuated any effects that the reason manipulation might have produced on its own. This raises concerns that the reason manipulation was not sufficiently differentiated from the consequences manipulation. Indeed, participants seemed to give the police officer the benefit of the doubt even in our control conditions, as the no reason condition was perceived as similarly justified to the other-focused condition.

The nature of the scenario itself may also explain why participants assumed a prosocial motive even when no reason was given. In our experiment, we manipulated whether the officer stated support for or opposition to a jaywalking law, but in both conditions, the officer's stated attitude was coupled with the information that suggested that the officer was taking a stand "for the people." These initially stated reasons may have been perceived as rooted in prosocial motives, ultimately trumping the reason that the officer gave after the fact. Given these potential threats to the construct validity of our study, we recommend that future research create a more ambiguous situation to differentiate the reason framings.

With these limitations in mind, we also acknowledge the strengths of this research. Our online experimental design allowed us to control for threats to internal validity. The online and anonymous administration of the study also helped diminish experimenter expectancy effects. Although our study was relatively low in population validity and somewhat questionable in its mundane realism, on average, our participants reported being more interested than not in the vignettes across experimental conditions. These data lend support to the idea that our study achieved some degree of experimental realism.

We recommend that future research studies expand beyond the modalities of written vignettes. The presentation of video or real-life simulations within the context of a field study could help to increase the mundane and experimental realism of the studies. Lammers et al. (2010) have shown that power may impact perceptions of hypocrisy. It is worth investigating whether different results emerge if the scenario did not involve a person with power, such as a police officer.

In summary, previous research has established that hypocrites face heavy social disapproval (Kreps et al., 2017; 
Jordan et al., 2017). As such, it is important to examine the factors that influence how hypocrisy is socially regarded. To our knowledge, we are one of the first research teams to directly examine how manipulating a harsh versus lenient consequence impacts perceptions of moral justification in comparison to a no hypocrisy control condition. Unlike the research conducted by Alicke et al. (2013), we were able to establish that it is both the harshness of consequence and the contradiction of values and behaviours that resulted in perceptions of lower moral justification. The harm caused by hypocrisy is an important consideration, while inconsistency and the reason behind an act of hypocrisy were not enough to determine perceptions of moral justification.

\section{Acknowledgements}

The authors would like to thank the members of the PSYC11H3 F LECO2 2018/9: Social Psychology Laboratory for their contributions in designing and conducting the study. We would also like to thank Karanbir Bhatti, Katalin A. Groe, Melody Hedayati, Tiffany V. Lieu, Raymond Luong, Heala Maudoodi, and Janeepan Uthayakumaran for their contributions to an earlier manuscript.

\section{Supplementary Materials}

The survey materials, along with the data and SPSS syntax files used for the statistical analyses, can be found at:

https://osf.io/vz352/? view_only=0fc5541487064fb88642f0718321 3ebe.

\section{Disclosures}

This research study was conducted as a class project for PSYC71H3 F LEC01 20199: Social Psychology Laboratory, Department of Psychology, University of Toronto Scarborough.

Instructor contact information: Kosha Bramesfeld, PhD, Department of Psychology, University of Toronto Scarborough, 1265 Military Trail, SW427A, Toronto, Ontario M1C 1A4, Canada. Email: kosha.bramesfeld@utoronto.ca 


\section{References}

Alicke, M., Gordon, E., \& Rose, D. (2013). Hypocrisy: What counts? Philosophical Psychology, 26(5), 673-701. https://doi.org/10.1080/09515089.2012.677397

Barden, J., Rucker, D. D., \& Petty, R. E. (2005). "Saying one thing and doing another": Examining the impact of event order on hypocrisy judgments of others. Personality and Social Psychology Bulletin, 31(11), 1463-1474. https://doi.org/10.1177/0146167205276430

Baron, J., \& Hershey, J. C. (1988). Outcome bias in decision evaluation. Journal of Personality and Social Psychology, 54(4), 569-579. https://doi.org/10.1037//00223514.54.4.569

Batson, C., \& Thompson, E. (2001). Why don't moral people act morally? Motivational considerations. Current Directions in Psychological Science, 10(2), 54-57. https://doi.org/10.1111/1467-8721.00114

Centers for Disease Control (2020, March 6). Pedestrian safety. https://www.cdc.gov/motorvehiclesafety/pedestrian_safety/index.html

Effron, D. A., \& Monin, B. (2010). Letting people off the hook: When do good deeds excuse transgressions? Personality and Social Psychology Bulletin, 36(12), 1618-1634. https://doi.org/10.1177/0146167210385922

Faul, F., Erdfelder, E., Lang, A.-G., \& Buchner, A. (2007). G*Power 3: A flexible statistical power analysis program for the social, behavioral, and biomedical sciences. Behavior Research Methods, 39, 175-191.https://doi.org/10.3758/BF03193146

Goodwin, G. P., Piazza, J., Rozin, P. (2014). Moral character predominates in person perception and evaluation. Journal of Personality and Social Psychology, 106(1), 148-168. https://doi.org/10.1037/a0034726

Merriam-Webster (n.d.). Hypocrisy. In Merriam-Webster dictionary. Retrieved February 16, 2021, from https://www.merriam-webster.com/dictionary/hypocrisy

Jordan, J. J., Sommers, R., Bloom, P., \& Rand, D. G. (2017). Why do we hate hypocrites? Evidence for a theory of false signaling. Psychological Science, 28(3), 356-368. https://doi.org/10.1177/0956797616685771 


\section{PRIMARY RESEARCH ARTICLE}

Kreps, T. A., Laurin, K., \& Merritt, A. C. (2017). Hypocritical flip-flop, or courageous evolution? When leaders change their moral minds. Journal of Personality and Social Psychology, 113(5), 730 -752. https://doi.org/10.1037/pspi0000103

Lammers, J., Stapel, D., \& Galinsky, A. (2010). Power increases hypocrisy: Moralizing in reasoning, immorality in behavior. Psychological Science, 21(5), 737-744. https://doi.org/10.1177/0956797610368810

Moon, J. W., Wright, R. R., Broadbent, C. S., Robinson, E. D. (2017)."The measure ye mete": Does prosocial priming lead to harsher moral judgment?. Psi Chi Journal of Psychological Research, 22(1). http://doi.org/10.24839/2325-7342.JN22.1.10 